phthalein. Indigocarmin and all these substances practically run parallel. It is simply a question of which can be read the best. They are all excreted by the same mechanism of the kidney. But we want to know, besides the excretory capacity of the kidney, any retention which may be present. It is perfectly possible for a kidney to have very markedly decreased excretion and at the same time to be able to excrete the substances that are necessary; so we make a test for retention. We select for this purpose the urea. Urea, creatinin and total nitrogen run practically proportionate. At present we are using urea because the method is simple. The concentrating power of the kidney is another function. So these three tests are all valuable, each different from the others. If there is a markedly increased excretion there will he, as a rule, retention. The concentrating power of the kidney is just as specific a function as the excretion of phenolsulphonephthalein itself, or of urea. It has been known for many years that the concentrating power of the kidney is one of the first things that suffer. There is probably only one disease in which the concentrating power is interfered with and the kidneys normal, and that is diabetes in syphilis.

Dr. Martin Krotoszyner, San Francisco: I cannot agree with Dr. Thomas' sweeping condemnation of cryoscopy, a method which, while it will never become popular among urologists on account of its difficult technic, is nevertheless one of the best tests for the determination of the functional capacity of the kidneys that we possess. On the basis of my constantly growing experience with that method, I venture the statement that in the comparatively few doubtful cases where functional tests are of paramount value, cryoscopy probably gives the most accurate prognostic information of all the tests at our command.

In closing I would once more ask you to try the intravenous phlorizin test on your own patients, as I think it possesses great advantages for comparative determination over other tests. I have not included the indigocarmin test in the tabulated comparative estimations, since that test is no applicable to quantitative determinations and thus is less fexible and less accurate than other tests. For purposes of comparative functional determinations I consider of the retention tests, the urea test, and of the excretion tests, the intravenous phlorizin test, the most commodious and accurate Particularly in doubtful cases the simultaneous application of the comparative urea, phenolsulphonephthalein, and phlorizin tests is apt in almost every instance to give adequate data on relative kidney function.

Dr. B. A. Thomas, Philadelphia: First answering Dr. Krotoszyner, I did not mean to infer that cryoscopy was absolutely valueless, but I do say, so far as its application to the total urine and blood is concerned, that this is practically true, which is the matter of importance relative to prostatectomy. Doubtless in the experience of a few it may still be serviceable so far as individual urines are concerned, but not of any more value than the information to be obtained from the employment of phenolsulphonephthalein or indigocarmin. Unfortunately it affords no more information than the more modern tests and adds difficulty in the technic.

I agree thoroughly with what Dr. Geraghty has said, that what we want to know respecting these various tests is which is simplest, most practical and most reliable. This is the avowed object of the paper. Undoubtedly, with some the results are sufficiently uniform that there need be no particular discrimination. Frequently a second test may and should be utilized to supplement and confirm the findings of the first. Certainly any one will admit that two or more tests are of more value than a single one.

I am just as anxious to adopt the best functional kidney test as any man here, but I have not been shown by my own experience that phenolsulphonephthalein is superior to indigocarmin so far as ease of application, interpretation or reliability of results go. The advantage of indigocarmin is the simplicity of its application. In the past our experience has been largely with the employment of indigocarmin intramuscularly, although recently we have been experimenting considerably with the intravenous use of this substance, using one tenth to one fifth of the intramuscular dose. Employed in this way intramuscular pain, the only objection, comparatively, with phenolsulphonephthalein, is overcome. If merely unilateral kidney function be desired, simple cystoscopy and the observance of the onset of the dye from the respective ureters-chromo-ureteroscopy-suffices to provide the desired information. If quantitative output be desired from the respective sides, obviously the ureters must be catheterized, as in the case of any other functional test, but this requirement with indigocarmin is the exception and not the rule. Herein lies the simplicity and practicability of the indigo test. I have seen cases in which one could not introduce into the ureteral orifices other than the tips of No. 5 catheters. Under such circumstances I defy any cystoscopist to apply the phenolsulphonephthalein test unilaterally. Yet it was a simple matter to determine the functions of the respective kidneys by employing indigo. Thus, in not a few instances, it is impossible to use any test that depends on synchronous bilateral ureteral catheterization.

\section{FACIAL PARALYSIS FOLLOWING PASTEUR ANTIRABIC TREATMENT}

\author{
REPORT OF A CASE OF FACIAL DIPLEGIA WITH \\ ONSET SEVENTY-THREE DAYS AFTER THE \\ BEGINNING OF PROPHYLACTIC \\ INOCULATIONS * \\ ROBERT L. LEVY, M.D. \\ BALTIMORE
}

A report of "treatment paralysis" following antirabic inoculations should in no sense be regarded as casting the slightest doubt on the advisability of carrying out the Pasteur treatment in cases in which it is indicated. Though hundreds of thousands of persons have, by this means, been prevented from developing an almost surely fatal disease, there are records of only 150 cases in which paralyses have followed its use. Of these patients, twenty-five died. ${ }^{1}$

It is desirable, however, that such cases be placed on record in order that a true estimate of their frequency may be made and, if possible, some light thrown on their obscure etiology.

The following history is of interest, first, because of the occurrence of isolated facial diplegia, an unusual form of "treatment paralysis," and, secondly, because of the remarkably long latent period between the beginning of treatment and the development of paralytic phenomena.

\section{REPORT OF CASE}

History.-A. U. N. (Med. No. 36828), a white man, aged 37, storekeeper, from Plymouth, N. C., was admitted to the medical service, Nov. 14, 1916, with paralysis of the face and pains in the head. The family history was unimportant. There had been no nervous diseases in the family. The general health of the patient had been good, though he was of extremely nervous temperament. At the age of 9 he had what his physician called "hemorrhagic fever," and at 21, 27 and 32, gonorrhea. He denied syphilis. He was a heavy smoker but a very moderate user of alcohol. He had been married eight years. There had been no children.

Aug. 20,1916, he was scratched on the arm by a supposedly rabid dog, which died a few days later. The wounds were cauterized with phenol. The head of the animal was sent by express to the laboratory of the North Carolina Board of Health, and examination of the brain revealed no Negri

* From the Medical Clinic of the Johns Hopkins Hospital.

1. A review and critical analysis of this group of cases may be found in Remlinger: Ann. de 1'Inst. Pasteur, 1905, 19, 625. Simon: Cen tralbl. f. Bakteriol., Orig., 1913, 68, 72. Fielder, F. S.: The Journat A. M. A., June 3, 1916, p. 1769. Geiger, J. C.: The Journal A. M. A. Feb. 17,1917, p. 513 
bodies. In spite of this assurance, he became extremely apprehensive and, against the advice of his physicians, insisted on taking the Pasteur treatment, which he received at the State laboratory in Raleigh from Aug. 31 to Sept. 19, 1916. On the fourth day of treatment he began to have sensations of "something crawling under his skin," first in one place, then in another. In addition, there were "neuralgic" pains in the lumbar region and in the muscles. These symptoms had persisted. Two weeks before admisșion he began to feel muscular twitchings, especially in the head, neck and legs. Six days before coming to Baltimore, a severe bitemporal headache appeared, and had not been relieved by sedatives. On rising in the morning, three days before admission to the hospital, he noticed that the left side of his face was paralyzed.

Physical Examination.-The patient was extremely neurotic and much concerned about his condition. He frequently
The urine contained no albumin. stigar or casts. Blood examination revealed: red blood cells, 4,346,000; white blood cells, 5,800; hemoglobin (Sahli), 82 per cent. The differential count was normal. The Wassermann reaction on the blood serum was negative.

November 20, the condition was unchanged. There was no further paralysis. Psychic symptoms were abating.

Lumbar puncture was performed. A clear fluid was obtained, containing eight cells and no excess of globulin. The Wassermann and colloidal gold reactions on the fluid were negative.

November 22, electrical examination of the facial muscles gave the following findings: Feeble response was obtained through the nerve on the left when stimulated with the faradic current. Direct stimulation of the muscles with the faradic current caused some contraction, but excitability was markedly decreased. When stimulated directly with the galvanic cur-

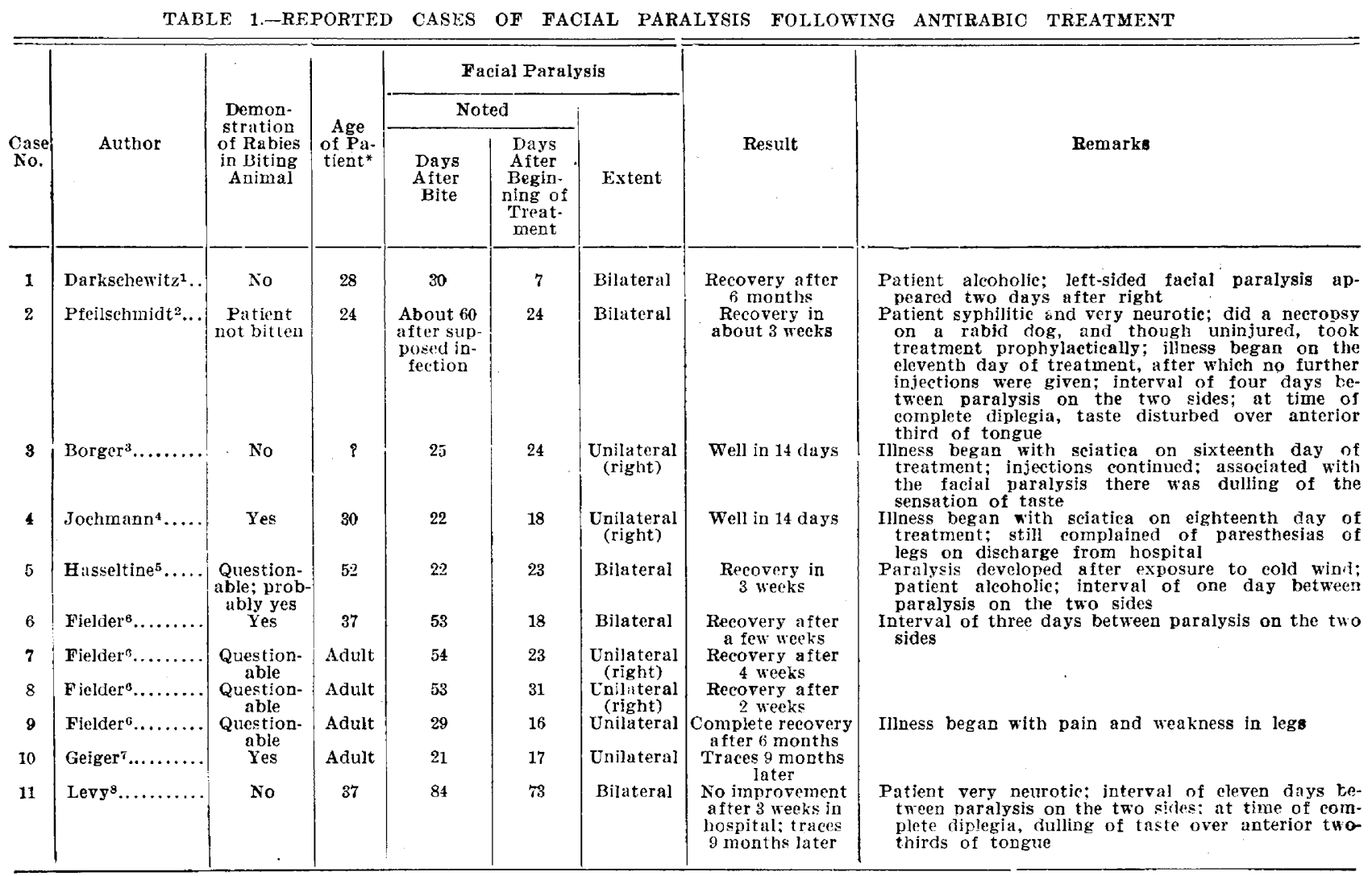

* The patients were all men with the exception of Case 10, in which the sex is not noted.

1. Darkschewitz: Neurol. Centralbl, 1898, 17, 98.

2. Pfeilschmidt: Neurol. Centralbl., 1908, 27, 1066.

3. Borger: Geneesk. Tijdschr. f. Nederl. Indië, 1911 (cited by Simon)

4. Jochmann: Deutsch. Ztschr. f. Nervenh., 1913, 47 and 48, 267.

5. Hasseltine: Pub. Health Rep., 1915, 30, 2226

6. Fielder: 'The Journal A. M. A., June 3, 1916, p. 1769

7. Geiger: The Jolr Nal A. M. A., Feb. 17, 1917, p. 513.

8. Levy: Present report.

became lacrimose during the recital of his history. The temperature, both on admission and subsequently, was norma!. He was large and well nourished. There were several pigmented scars about the left elbow, evidently the remains of his carbolized wounds.

There was complete left facial paralysis, without sensory disturbance on either the face or the tongue. There was marked lacrimation from the left eye.

The pupils reacted normally. There were no eye-muscle palsies. The eyegrounds were normal. The heart and lungs were clear. The blood pressure was $142 \mathrm{~mm}$. of mercury systolic and 92 diastolic. The liver and spleen were not felt. There were no fibrillary twitchings; no muscular weakness or atrophy. Neurologic examination, save for the facial paralysis and slightly exaggerated deep reflexes, was negative.

A special nose, throat and ear examination revealed no abnormalities. Both cochlear and vestibular divisions of the eighth nerves were intact. rent, the muscles responded more slowly on the left side than on the right, and there was decreased excitability. Cathodal closing contraction was greater than anodal closing contraction.

November 27, the patient complained of stiffness of the right corner of the mouth and of an increase in the "feeling of something crawling over the body." There was slight weakness of the lower right side of the face.

November 28 , the entire right side of the face was paralyzed, except for the right frontalis muscle, which contracted slightly. There was great difficulty in keeping food within the oral cavity. The expression was mask-like.

November 30 , the patient was very nervous. Control of the right half of the face was now completely lost. He was having local electric treatment every other day.

December 4, the patient complained of numbness of both legs. There was no objective sensory disturbance over the body. There was marked dulling of taste sensation over the 
anterior two thirds of the tongue on both sides. He frequently mistook bitter for sweet, salt for sour, etc., and was much concerned about his condition. He left the hospital at his own request. He was advised to continue electrical treatment to the face at home.

A note from the patient's physician, June 25, 1917, stated that "Mr. N. is not taking any treatment now. He is very little better, judging from the appearaance of his face."

The following extracts from a letter received, Nov. 20, 1916. from Dr. C. A. Shore, director of the Laboratory of Hygiene of the North Carolina State Board of Health, furnish further interesting data:

"Mr. N. received antirabic treatment in this laboratory from August 31 to September 19, inclusive. I do not think that Mr. N. needed this treatment and I strongly advised against it. In the first place, the suspected dog did not bite him, but merely scratched his arm, on August 20. The dog died, according to Mr. N.'s statement, on August 24. The head was expressed to us; the brain was in good condition when received and the microscopic examination failed to show any Negri bodies.

"We have treated 1,620 patients in this laboratory, and from this number, excluding that of $\mathrm{Mr}$. N., there has been only me case of paralysis. This developed on the fourteenth day of treatment. The patient had a complete paralysis of the lower limbs and partial paralysis of the muscles of the arms and trunk. I have never been sure whether it was a case of infintile paralysis or a paralysis resulting from the antirabic treatment. The patient was 15 years old at the time and made a complete récovery.

"The schedule of treatment which we use in this laboratory at present is that recommended by the Hygicnic Laboratory of the U. S. Public Health Service."

\section{COMMENT}

A majority of cases of "treatment paralysis" have developed while the patients were receiving the injections; about one quarter, according to Simon, within sevell days thereafter. Fielder cites an instance of facial paralysis with onset thirty-one days after beginning treatment, and Geiger a case of neuritis, with spasmodic contraction of the neck muscles, occurring forty-five days after the first inoculation.

In spite of the fact that in the case here reported seventy-three days elapsed between the beginning of treatment and the onset of paralysis, there can be no reasonable doubt as to the direct relationship between the antirabic therapy and the facial diplegia. Symptoms began after the fourth injection and were similar to those described in other instances of "treatment paralysis." Furthermore, the gradual development of paralysis of the right side of the face while the patient was under careful supervision in the hospital ward makes it highly unlikely that this was an example of simple Bell's palsy.

In the literature are to be found records of ten other cases of isolated facial paralysis following antirabic treatment. These are collected in the accompanying table.

An analysis of the table brings out the following points :

1. In at least three instances, the biting animal was proved nonrabic.

2. All cases in which complete data are available occurred in adult males.

3. The earliest appearance of the facial paralysis was on the seventh day, the latest, exclusive of the present case, was on the thirty-first day after beginning treatment.

4. In six cases the facial paralysis was unilateral, in five bilateral.
5. In the bilaterai cases, an interval of from one to eleven days elapsed between the development of paralysis on the two sides. In no instance were both sides of the face paralyzed at onset.

6. Dulling of taste over the anterior portion of the tongue accompanied the facial paralysis in three instances.

7. Nine of the eleven patients recovered. In two cases there were traces of paralysis nine months later.

8. Of 150 reported cases of treatment paralysis, eleven, or 7.3 per cent., have been of the isolated facial variety.

The etiology of these paralyses is still in doubt. The various theories as to their causation have recently been adequately discussed by Fielder, who sums them up as follows: "There is no doubt that in most of the cases, at least, the symptoms are caused, not by street virus infection, modified by the treatment, but by the treatment itself either through the medium of fixed virts infection or through the action of a toxin, or both. In any event there must be a special idiosyncrasy on the part of the patient. Otherwise the cases would be enormously more frequent than they are." Alcoholic, syphilitic and neurotic individuals are said to be particularly susceptible.

Obviously no special form of therapy based on etiologic considerations can be carried out.

\section{New and Nonofficial Remedies}

The following additional articles have been accepted as Conforming to the rules of the Council on Pharmacy and Chemistry of the American Medical Association for admission to New and Nonofficial Remedies. A copy of THE RULES ON WHICH THE COUNCIL baSES ITS ACTION WILl bE SENT ON APPLICATION.

W. A. Puckner, Secretary.

BORCHERDT'S MALT SUGAR.-A mixture containing approximately maltose 87.40 per cent., dextrin 4.35 per cent., protein 4.40 per cent., ash 1.90 per cent., moisture 1.95 per cent.

Actions and Uses.-Borcherdt's malt sugar may be used where maltose is indicated in the feeding of infants, particularly in the treatment of constipation. The nutritive value of $500 \mathrm{Gm}$. of Borcherdt's malt sugar corresponds to approximately 1,985 calories.

Dosage.-It may be used in all milk mixtures in the same proportions as lactose (sugar of milk), that is, one ounce of Borcherdt's malt sugar (two tablespoonfuls) to a 20 ounce mixture.

Manufactured by The Borcherdt Malt Extract Co., Chicago. No U. S. patent. U. S. trademark No. 64467.

Borcherdt's malt sugar is prepared by the action of malt diastase on starch.

It is a yellowish-brown powder having a malt odor and a sweet taste. It is somewhat hygroscopic and very soluble in water.

If a few drops of iodine test solution be added to an aqueous solu. tion of Borcherdt's malt sugar, a reddish-violet but not a blue color is produced.

The maltose content of Borcherdt's malt sugar is determined according to the method described in U. S. Dept, of Agric., Bureau of Chem Bulletin No 107 pare 46.

The protein content of Borcherdt's malt sugar is calculated from the nitrogen content $(\mathrm{N} \times 6.25)$ as determined by the methorl described in U. S. Dept. of Agric., Bureau of Chem., Bulletin No. 107, page 5 .

TYRAMINE-ROCHE - Para - Hydroxy - Phenyl - EthylAmine Hydrochloride. - $\mathrm{OH} . \mathrm{C}_{6} \mathrm{H}_{4} . \mathrm{CH}_{2} . \mathrm{CH}_{2} . \mathrm{NH}_{2} \mathrm{HCl}$ - The hydrochloride of the base para-hydroxy-phenyl-ethyl-amine $\mathrm{OH} . \mathrm{C}_{6} \mathrm{H}_{4} \cdot \mathrm{CH}_{2} \cdot \mathrm{CH}_{2} \cdot \mathrm{NH}_{2}$ obtained synthetically.

Action, Uses and Dosage.-See New and Nonofficial Remedies, 1917, p. 105, under Tyramine.

Manufactured by F. Hoffmann-La Roche \& Co., Basel, Switzerland (The Hoffmann-La Roche Chemical Works, New York). No U. S. patent or trademark. 